\title{
Characterisation of anodic oxide films on zirconium formed in sulphuric acid: XPS and corrosion resistance investigations
}

\author{
Maciej Sowa $^{1}$ Dobrochna Lastówka ${ }^{1}$ Andrey I. Kukharenko ${ }^{2,3}$. \\ Danila M. Korotin ${ }^{2,3}$ - Ernst Z. Kurmaev ${ }^{2,3}$ - Seif O. Cholakh ${ }^{3} \cdot$ Wojciech Simka $^{1}$
}

Received: 9 May 2016 / Revised: 26 July 2016 / Accepted: 12 August 2016 / Published online: 20 August 2016

(C) The Author(s) 2016. This article is published with open access at Springerlink.com

\begin{abstract}
Present work describes investigations of a two-step process consisting of galvanostatic anodising in a $1 \mathrm{M} \mathrm{H}_{2} \mathrm{SO}_{4}$ solution at $100 \mathrm{~mA} \mathrm{~cm}^{-2}$ up to the limiting voltages of 20,60 , 80,100 and $120 \mathrm{~V}$, directly after which potentiostatic regime was employed and the current was allowed to drop. The total treatment time ( $5 \mathrm{~min}$ ) was held constant for all samples. The treatment was carried out to improve the corrosion resistance of zirconium in physiological conditions, which was determined by electrochemical evaluation in Ringer's solution. XPS studies revealed that after anodising sulphur was incorporated into the oxide film in the form of sulphated zirconia. The maximum content of sulphate in the oxide layer was observed after anodising at $80 \mathrm{~V}$. Anodising at higher voltages resulted in formation of coatings with decreasing amount of sulphur. It was found that there is a strong correlation between the sulphur content in the oxide layers and the measured corrosion current density. On the other hand, the pitting corrosion resistance seemed to be unaffected by the presence of $\mathrm{S}$ and it was improving with the increasing limiting voltage of the treatment.
\end{abstract}

Keywords Zirconium $\cdot$ Anodic oxidation $\cdot$ Corrosion resistance $\cdot$ Sulphuric acid $\cdot \mathrm{X}$-ray photoelectron spectroscopy

Wojciech Simka

wojciech.simka@polsl.pl

1 Faculty of Chemistry, Silesian University of Technology, B. Krzywoustego Street 6, 44-100 Gliwice, Poland

2 M.N. Mikheev Institute of Metal Physics of the Ural Branch of Russian Academy of Sciences, S. Kovalevskoi Street 18, 620990 Yekaterinburg, Russia

3 Institute of Physics and Technology, Ural Federal University, Mira Street 19, 620002 Yekaterinburg, Russia

\section{Introduction}

Zirconium is a valve metal, i.e. it spontaneously forms a thin, tightly adhering zirconia passive layer onto its surface when exposed to an oxidising environment, be it oxygen from air or other oxidiser [1]. Because of its barrier properties, characteristic for valve metals, zirconia film is capable of preventing current flow under anodic polarisation because of continuous growth of non-conducting oxide layer on top of the naturally existing one. The growth of the oxide is allowed because of the migration of defects $\left(\mathrm{M}^{\mathrm{n}+}\right.$ ions or oxygen vacancies) in the passive layer, and it can take place either at the metal/oxide interface, oxide/electrolyte interface or in the bulk of the oxide, depending on the transport numbers of a particular defect. The metal ions can be carried to the oxide/electrolyte interface and hydrolysed by the aqueous solution forming fresh oxide, while oxygen vacancies generated at the metal/oxide interface can be re-occupied at the oxide/electrolyte interface by oxygen ions $[2,3]$. If the polarisation of such metal would be reversed (cathodic), the flow of current would still be blocked; however, only at very low voltages beyond which partial reduction of the barrier oxide occurs and further flow of current is no more hampered [4]. Depending on the conditions of anodic oxidation of zirconium, i.e. voltage, current density, electrolyte composition and temperature, it is possible to grow oxide layers as thick as several hundred nanometers [5]. There is a limit above which uniform oxide growth cannot be sustained because of oxide breakdown. It was demonstrated by [6], that galvanostatic anodic oxidation of zirconium in sulphuric acid leads to stress-induced oxide breakdown above $120 \mathrm{~V}$.

Zirconium and zirconia are biocompatible, and therefore, they are eagerly applied in the field of biomedical engineering, especially for dental implants [1]. Zirconia has been known to be a promising ceramic material since in the late 1960s $[7,8]$. 
Its first successes as femoral head material for hip replacement implants were noted not long after.

Proper preparation of biomaterial surfaces for endoprostheses involves a wide array of treatments, among which a few electrochemical techniques can be discerned, such as electrochemical polishing [9], mangetoelectropolishing [10], plasma electrolytic oxidation [11] and conventional anodic oxidation [12]. The latter is a widespread technique for surface finishing of metallic implants because it realises two goals: increases biocompatibility of metallic surfaces by forming an oxide layer and it inhibits corrosion of an implant $[4-6,8,12]$. In the present study, pure zirconium was subjected to chemical etching and galvanostatic anodisation in a sulphuric acid solution at different voltages. Resulting anodic layers were characterised using scanning electron microscopy (SEM) and $\mathrm{X}$-ray photoelectron spectroscopy (XPS). To assess the corrosion resistance of anodised zirconium in physiological conditions, electrochemical corrosion tests were performed in Ringer's solution at $37^{\circ} \mathrm{C}$.

\section{Materials and methods}

\section{Sample preparation}

Square coupons $(10 \times 10 \mathrm{~mm})$ of pure zirconium (BIMO Metals, Wrocław, Poland) were used throughout the measurements. Pretreatment comprised of mechanical grinding up to \#800 grit size, chemical etching in a solution containing $1 \mathrm{M}$ $\mathrm{HF}$ and $4 \mathrm{M} \mathrm{H}_{2} \mathrm{SO}_{4}$ for $2 \mathrm{~min}$ and degreasing in a 2-propanol/ water mixture $(1: 1 \mathrm{vol}$.) for another $2 \mathrm{~min}$. The pretreated samples were dried in a stream of air. Etched samples $(\mathrm{Zr}$ $0 \mathrm{~V}$ sample) were then $\mathrm{DC}$ anodised in a $1 \mathrm{M} \mathrm{H}_{2} \mathrm{SO}_{4}$ solution using a two-step procedure. First, the sample was anodised under galvanostatic conditions $\left(100 \mathrm{~mA} \mathrm{~cm}^{-2}\right)$ up to a range of limiting voltages $(\mathrm{Zr} 20-120 \mathrm{~V})$, then the process was switched to voltage control and the current was allowed to drop, so as to keep the voltage constant. The total processing time was set to $5 \mathrm{~min}$. The two-step character of the procedure can be observed in Fig. 1. A high-voltage DC power supply (PWR 600H, Kikusui, Japan) was used during the treatment. Zirconium coupons served as anodes while the cathode was made from titanium. Electrolytic cell was cooled with a cryostat (temperature was set to $15^{\circ} \mathrm{C}$ ). After anodising, the samples were rinsed thoroughly with distilled water to get rid of the residual electrolyte.

\section{Surface morphology investigations}

Surface morphology of the zirconium specimens was studied using a scanning electron microscope (accelerating voltage $=15$ kV; Phenom ProX, Phenom-World BV, Netherlands).

\section{Surface composition analysis}

Chemical composition of the resulting anodic oxide films was determined using X-ray photoelectron spectroscopy (PHI XPS Versaprobe 5000 spectrometer, ULVACPhysical Electronics, USA). The spectrometer was equipped with a spherical quartz monochromator and energy analyser working in the binding energy (BE) range of $0-1500 \mathrm{eV}$, an electrostatic focusing system and magnetic screening. The energy resolution of $\mathrm{Al} \mathrm{K} \alpha \mathrm{X}$-ray source was approximately $0.5 \mathrm{eV}$ and spot size of the beam was equal to $200 \mu \mathrm{m}$. Prior to measurements, the samples were incubated in ultra-high vacuum $\left(10^{-7} \mathrm{~Pa}\right)$ for $24 \mathrm{~h}$. The ULVAC-PHI MultiPak 9.2 software was used for the spectra post-processing and the residual background was removed by the use of the Tougaard method. The energy of $\mathrm{C} 1 \mathrm{~s}$ core excitation $(\mathrm{BE}=284.5 \mathrm{eV})$ was used to calibrate the measured XPS spectra.
Fig. 1 Voltage-time and current density-time relationships for the $\mathrm{Zr}$ sample anodised up to $120 \mathrm{~V}$, showing the two-step anodisation procedure used for preparation of the $\mathrm{Zr}$ specimens. The inset shows the magnified relationship of the first step anodisation

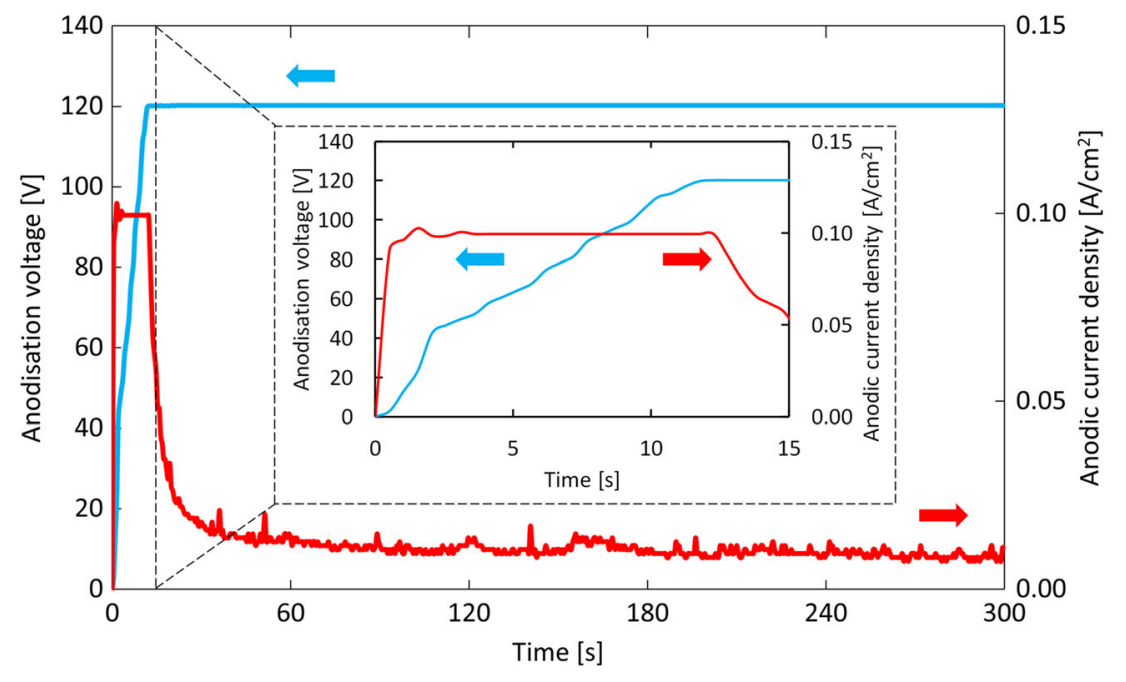




\section{Corrosion resistance experiments}

Electrochemical experiments were used to determine corrosion resistance of the modified surfaces of zirconium. All measurements were performed in Ringer's solution $\left(8.6 \mathrm{~g} \mathrm{dm}^{-3} \mathrm{NaCl}, 0.3 \mathrm{~g} \mathrm{dm}^{-3} \mathrm{KCl}\right.$ and $0.48 \mathrm{~g} \mathrm{dm}^{-3} \mathrm{CaCl}_{2} \cdot 6 \mathrm{H}_{2} \mathrm{O}$; Baxter, USA) at $37{ }^{\circ} \mathrm{C}$ to simulate physiological environment. A $250 \mathrm{~cm}^{3}$ corrosion measurements cell adopted for flat samples (Biologic Science Instruments, France), filled with Ringer's solution was used for electrochemical analyses. A zirconium specimen served as the working electrode, whereas saturated calomel electrode (SCE) with a HaberLuggin capillary was used in the experiments as the reference electrode. A platinum mesh was employed as the auxiliary electrode. The experiments were conducted using PARSTAT 4000 potentiostat-galvanostat (Princeton Applied Research, USA) equipped with an FRA unit and operated by VersaStudio software. The following procedures were used:

1. The sample was immersed in Ringer's solution, while the open-circuit potential (OCP, $E_{\mathrm{OC}}$ ) was recorded for $7200 \mathrm{~s}$.

2. Linear polarisation resistance (LPR) was then performed with the scan in the potential range $\pm 30 \mathrm{mV}$ vs. OCP (scan speed $=0.1 \mathrm{mV} \mathrm{s}^{-1}$ ).

3. Followed by the cathodic ( 0 to $-200 \mathrm{mV}$ vs. OCP) and anodic $(0$ to $+400 \mathrm{mV}$ vs. OCP $)$ potentiodynamic polarisation scans (scan speed $=1 \mathrm{mV} \mathrm{s}^{-1}$ ).

4. Finally, the potentiodynamic polarisation in the potential range from $+400 \mathrm{mV}$ vs. OCP to $E_{\text {break }}$ vs. SCE (scan speed $=10 \mathrm{mV} \mathrm{s}^{-1}$ ) was realised.
Corrosion current density, $i_{\text {corr }}$, was calculated according to Stern-Geary method [13]:

$i_{\text {corr }}=\frac{\beta_{\mathrm{a}} \beta_{\mathrm{c}}}{2.3\left(\beta_{\mathrm{a}}+\beta_{\mathrm{c}}\right)} \frac{1}{R_{\mathrm{p}}}=\frac{B}{R_{\mathrm{p}}}$

where $\beta_{\mathrm{a}}$ and $\beta_{\mathrm{c}}$ are anodic and cathodic Tafel slopes and $R_{\mathrm{p}}$ denotes polarisation resistance (extracted from LPR).

\section{Results and discussion}

Exemplary voltage-time and current time progressions recorded during anodisation of $\mathrm{Zr}$ in $1 \mathrm{M} \mathrm{H}_{2} \mathrm{SO}_{4}$ up to $120 \mathrm{~V}$ are shown in Fig. 1. During the first moments of the anodisation, constant current $\left(100 \mathrm{~mA} \mathrm{~cm}^{-2}\right)$ was flowing through zirconium specimens (Fig. 1 inset). The anodic current was associated with the growth of the oxide layer on zirconium. The voltage of anodisation was increasing with time due to the barrier properties the oxide layer, which resistance increased linearly with time up to ca. $40 \mathrm{~V}$. Then, the slope of the curve decreased slightly which was concurrent with the onset of evolution of oxygen gas. The intensity of evolution of gas was increasing with the applied voltage. Once the limiting voltage was attained, the current dropped to a value of approximately $10 \mathrm{~mA} \mathrm{~cm}$.

SEM images of zirconium specimens after chemical etching and after anodic oxidation in sulphuric acid up to a range of limiting voltages $(20-120 \mathrm{~V})$ are presented in Fig. 2. Characteristic scratches after grinding were removed after chemical etching (Fig. 2a). The surface microstructure of the anodised zirconium samples closely resembled the one observed on the samples which were subjected to etching alone (Fig. 2b), regardless of the applied limiting voltage. The growth of the oxide was
Fig. 2 SEM images of zirconium surface after chemical etching in $\mathrm{HF}$ and $\mathrm{H}_{2} \mathrm{SO}_{4}$ solution (a) and after anodising at $120 \mathrm{~V}$ (b). Below the micrographs, macroscopic images revealing the colours of the surfaces are presented
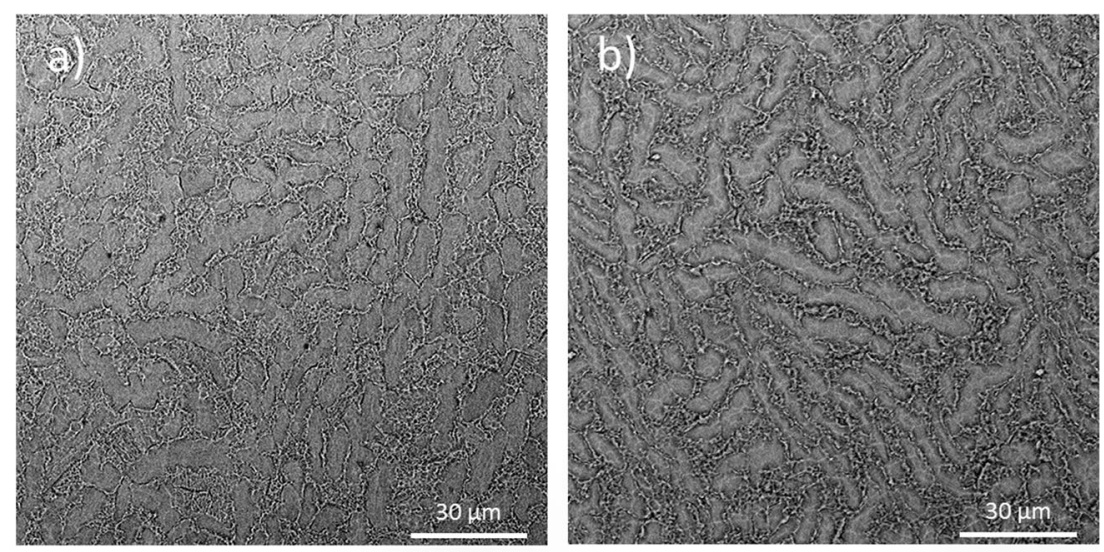

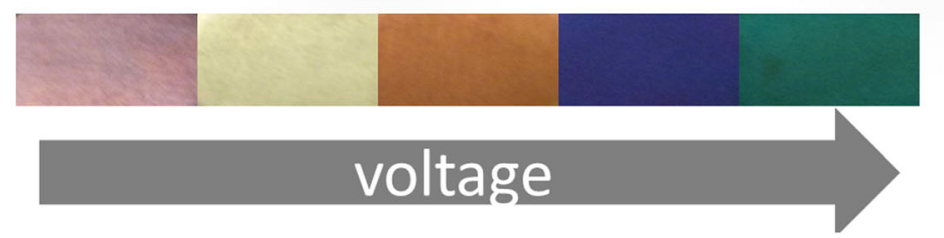


uniform which gave rise to interference colours [14] (Fig. 2). Oxide breakdown was not observed during the treatment.

In Fig. 3, XPS survey and core excitation spectra of Zr after chemical etching ( $\mathrm{Zr} 0 \mathrm{~V})$ and after subsequent anodising $(\mathrm{Zr}$
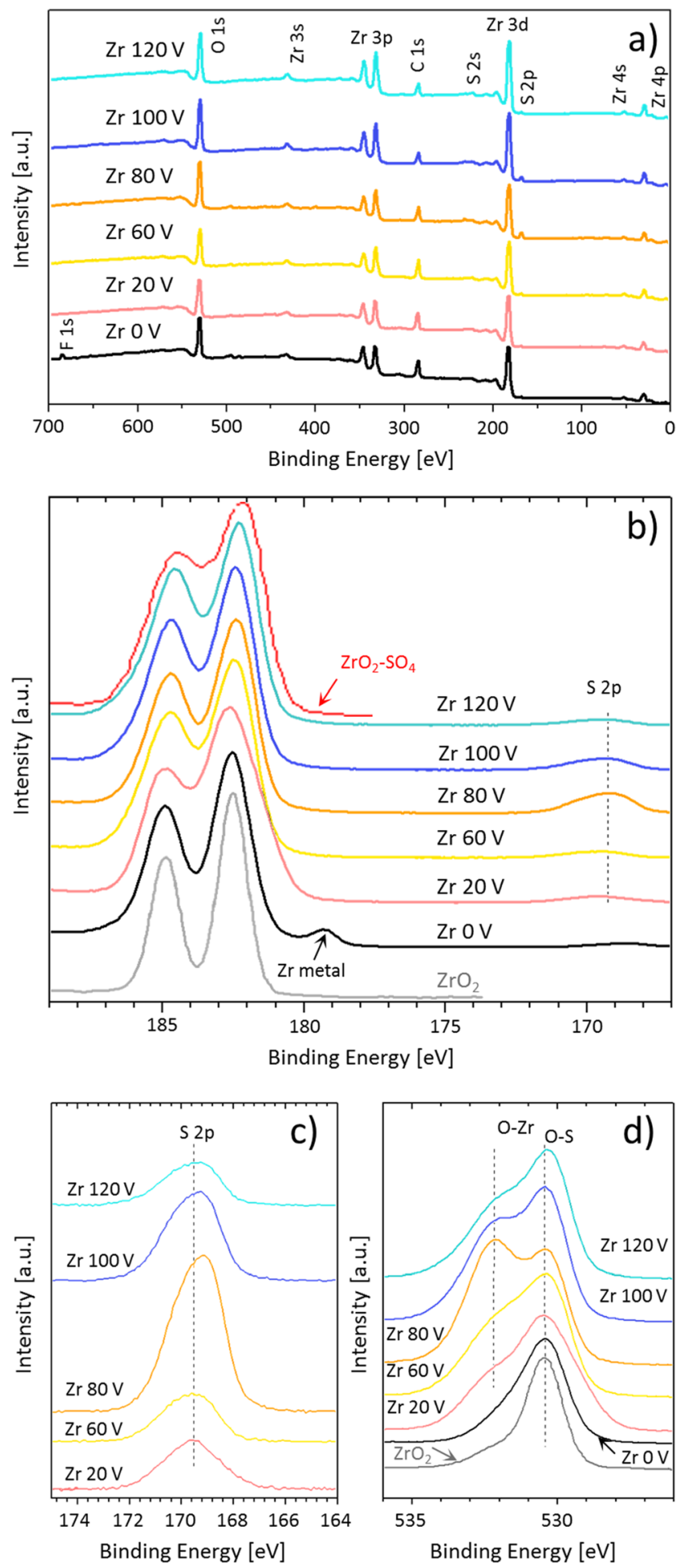

Fig. 3 XPS survey spectra (a) and Zr 3d (b), S 2p (c) and O 1s (d) core excitation spectra determined for the $\mathrm{Zr}$ anodised in sulphuric acid solution
20-120 V) are presented. XPS survey spectrum of chemically etched $\mathrm{Zr}$ consists of $\mathrm{F} 1 \mathrm{~s}$ (due to pretreatment in $\mathrm{HF}$ ), $\mathrm{O} 1 \mathrm{~s}, \mathrm{Zr}$ $3 \mathrm{~s}, \mathrm{Zr} 3 \mathrm{p}, \mathrm{C} 1 \mathrm{~s}, \mathrm{Zr} 3 \mathrm{~d}, \mathrm{Zr} 4 \mathrm{~s}$ and $\mathrm{Zr} 4 \mathrm{p}$ lines. After the anodic treatment in $\mathrm{H}_{2} \mathrm{SO}_{4}$, additional lines of $\mathrm{S} 2 \mathrm{~s}$ and $\mathrm{S} 2 \mathrm{p}$ were detected. The analysis of XPS Zr 3d spectra (Fig. 3b) shows that there was a large overlap between the spectra of all samples and a reference spectrum of $\mathrm{ZrO}_{2}$ [15]. In the spectrum of chemically etched zirconium, a trace of metallic $\mathrm{Zr}$ signal was detected which indicates that the oxide layer was thin enough to detect the signal from the underlying metal. These signals were not observed in the spectra of the anodised $\mathrm{Zr}$. A small low-energy shift and broadening in the XPS $\mathrm{Zr} 3 \mathrm{~d}$-spectra is observed with increasing anodisation voltage towards the signal characteristic for sulphated zirconia $\left(\mathrm{ZrO}_{2}-\mathrm{SO}_{4}\right)$ [16]. It is important to note that the detectable signals of $\mathrm{S} 2 \mathrm{p}$ were
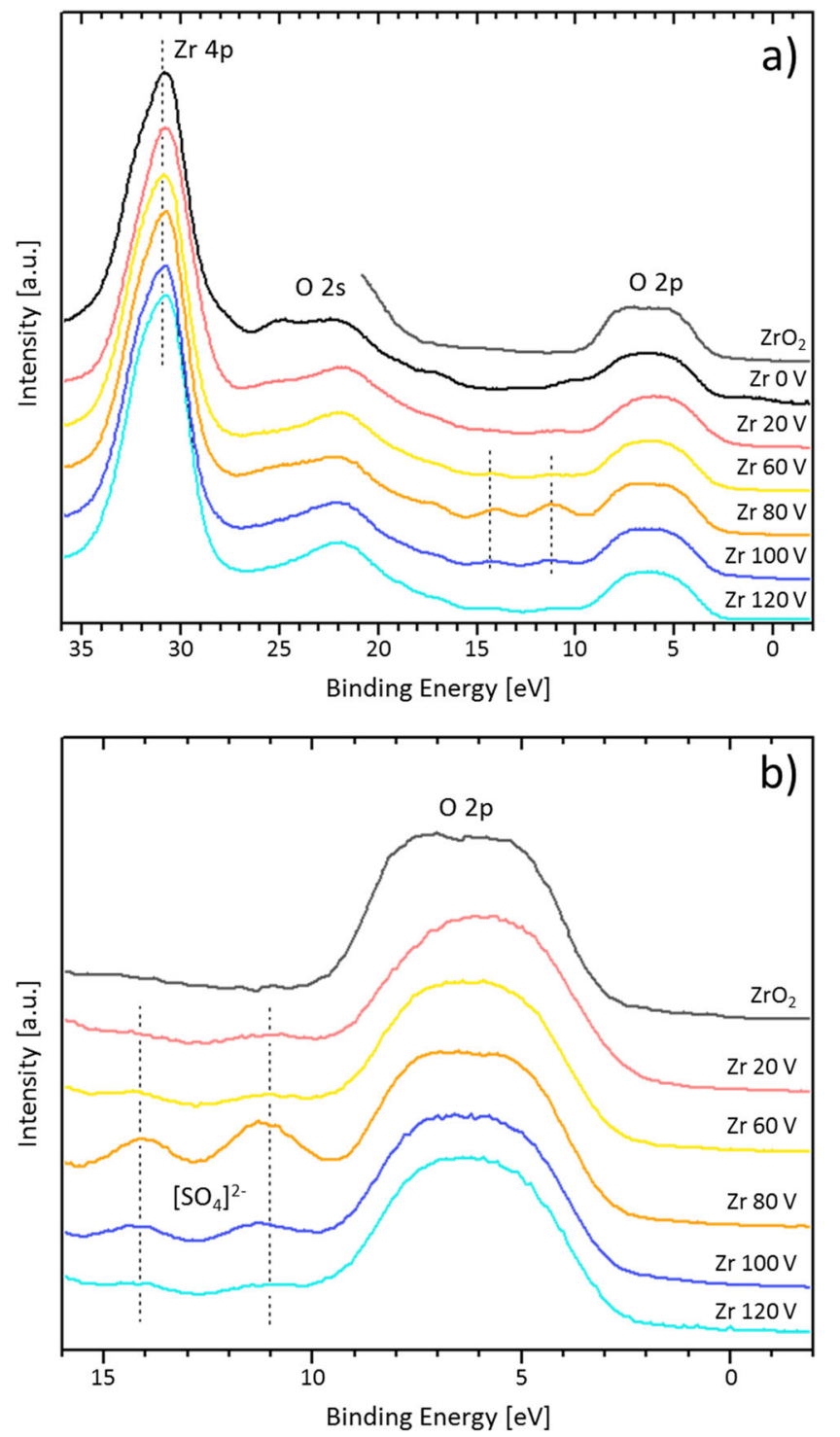

Fig. 4 XPS valence spectra measured for the $\mathrm{Zr}$ samples anodised in sulphuric acid solution (a) and the magnification of the spectra at $\mathrm{BE}$ 16-0 eV (b) 
Fig. 5 Corrosion resistance of $\mathrm{Zr}$ before and after anodic treatment in sulphuric acid solution presented as open-circuit potential vs. time dependence (a), LPR plots (b), Tafel plots (c) and long-range polarisation plots $(\mathbf{d})$

found after the anodic treatment at all voltages $(20-120 \mathrm{~V})$ with maximum content at $80 \mathrm{~V}$ (see also Fig. 3c).

The binding energies in the $\mathrm{S} 2 \mathrm{p}$ spectra found close to $169.5 \mathrm{eV}$ were similar to that of $\mathrm{CuSO}_{4}$ [17], which might suggest the presence of sulphate ions (Fig. 3c). This conclusion was confirmed by the analysis of XPS O 1s spectra (Fig. 3d), where besides the signal from $\mathrm{O}-\mathrm{Zr}$ bonds at $530.5 \mathrm{eV}$ (corresponding to the formation of $\mathrm{ZrO}_{2}$ [15]), an additional line at $\sim 532 \mathrm{eV}$ was observed. The latter can be related to the formation of $\mathrm{O}-\mathrm{S}$ bonds [18] with maximum intensity after treatment at $80 \mathrm{~V}$.

The XPS valence band (VB) spectra of $\mathrm{Zr}$ before and after anodic treatment in $\mathrm{H}_{2} \mathrm{SO}_{4}$ are presented in Fig. 4. It is noteworthy that the shapes of the XPS valence band spectra of $\mathrm{Zr}$ specimens at $0-10 \mathrm{eV}$ (Fig. 4a) were found to be very similar to that of $\mathrm{ZrO}_{2}$ [12], yet some differences after the modifications could be distinguished. After anodic treatment at 20$120 \mathrm{~V}$ the additional features at 11.0 and $14.1 \mathrm{eV}$ were detected with maximum intensities for the specimen anodised at $80 \mathrm{~V}$ (Fig. 4b). The energy difference of their BEs of $3.1 \mathrm{eV}$ is found to be very close to that of sulphates $(2.9-3.0 \mathrm{eV})$ [19].

The comparison of XPS VB spectra after anodising at 20$120 \mathrm{~V}$ with electronic structure calculations [20] for $\mathrm{Na}_{2} \mathrm{SO}_{4}$ showed that these additional features arise from $3 \mathrm{~s}$ states of sulphur $(\sim 13 \mathrm{eV})$ and $2 \mathrm{p}$ states of oxygen $(\sim 10 \mathrm{eV})$ of $\mathrm{SO}_{4}{ }^{2-}$ sulphate ion which can be related to the formation of sulphated zirconia [21-23].

This counterintuitive finding that sulphur incorporation in the oxide layer was on its peak at $80 \mathrm{~V}$ perhaps can be explained by taking a closer look how the anodic oxidation process is realised. Anodising of zirconium was conducted at constant current density which may imply that the coating was growing at a constant rate, given that the formation of coating was the only electrode reaction taking place at an oxide/ electrolyte interface. In fact, it is reasonable to assume that at low voltages (tens of volts) most of the charge is spent on the thickening of the naturally occurring passive layer (first $2 \mathrm{~s}$ of the process - Fig. 1). This is usually evidenced by the uniform rise in voltage with time during the process. However, at some point, the voltage is high enough that electronic conduction through metal oxide film can occur and oxygen bubbles generation is noticeable on the surface of the treated metal (slight decrease in the voltage-time slope-Fig. 1) [14]. The intensity of the generation of oxygen bubbles was increasing with the increasing treatment time, so at higher voltages more of the charge was devoted to the oxygen bubbles formation and the rate at which the oxide is formed drops, and consequently, sulphate ions could have been incorporated to the lesser extent.
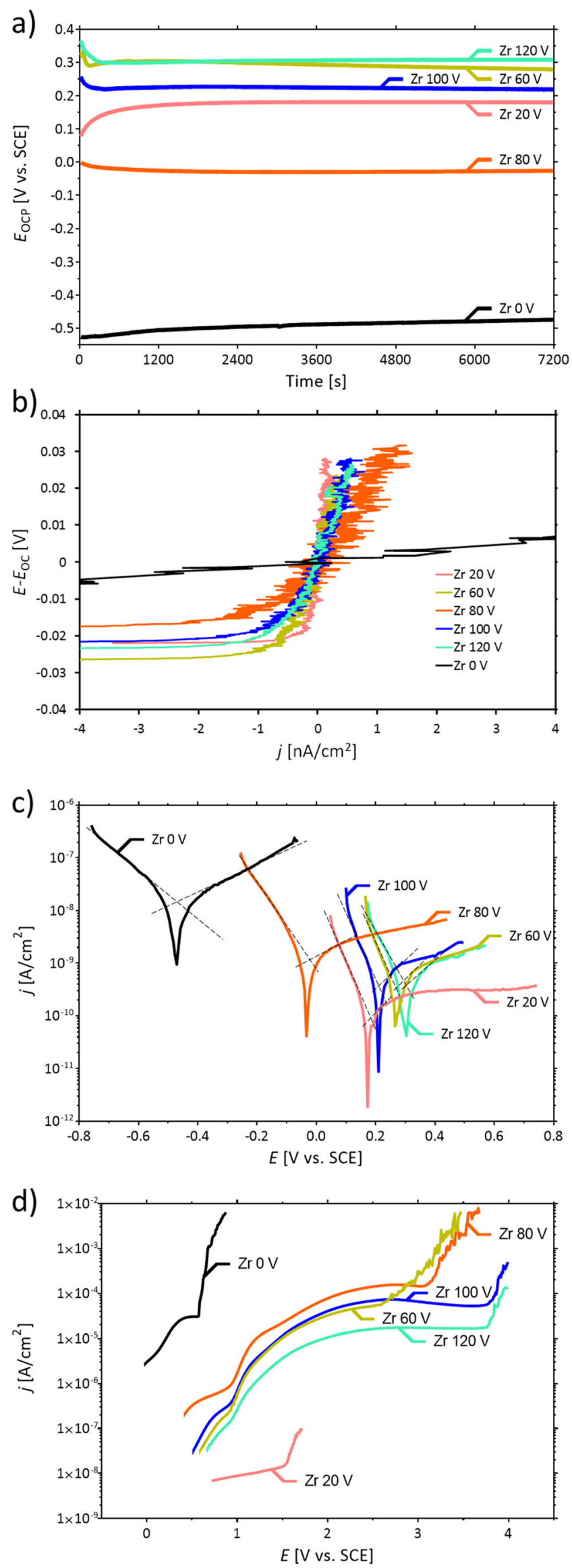
Anodising in $1 \mathrm{M} \mathrm{H}_{2} \mathrm{SO}_{4}$ at voltages beyond $120 \mathrm{~V}$ results oxide breakdown, which was assigned to the internal stress arising during oxide growth by [6]. From the results of Sloppy JD et al., it was found that anodisation of tantalum in dilute phosphoric acid solution led to incorporation of phosphates into the oxide. This was explained by the transport of $\mathrm{Ta}^{5+}$ ions to the oxide/electrolyte interface where it was hydrolysed or combined directly with phosphate species [2]. There might by another explanation to this problem. The process was not conducted under stirring, which might have had an effect on the surface concentration of $\mathrm{SO}_{4}{ }^{2-}$ ions on $\mathrm{Zr}$, since the amount of $\mathrm{S}$ species in the vicinity of surface decreased with time as they were incorporated to the oxide. Therefore, at high voltages (100 and $120 \mathrm{~V}), \mathrm{S}$ content was lower than that in the coatings obtained after anodisation up to $80 \mathrm{~V}$.

Corrosion resistance of zirconium before and after anodising in sulphuric acid solution was assessed in Ringer's solution at $37^{\circ} \mathrm{C}$. First, open-circuit potential of each sample was measured for $7200 \mathrm{~s}$ (Fig. 5a). For the zirconium sample subjected only to surface pretreatment ( $\mathrm{Zr} 0 \mathrm{~V}$ sample), the value of $E_{\mathrm{OC}}$ was increasing throughout the experiment and after $7200 \mathrm{~s}$, it reached the value of $-474.5 \mathrm{mV}$ vs. SCE (Table 1). This behaviour can be attributed to the surface passivation, often encountered for the valve metals [1]. Figure 5a shows that anodising led to the increase in the value of $E_{\mathrm{OC}}$ of $\mathrm{Zr}$ in Ringer's solution. The values of the $E_{\mathrm{OC}}$ for the anodised $\mathrm{Zr}$ surfaces stabilised after approximately $1800 \mathrm{~s}$ and remained nearly constant until the end of experiments. From the results, it can deduce that the higher limiting voltage of anodisation (20-120 V) led to the generation of thicker zirconium oxide layer which corresponds to the more positive value of $E_{\mathrm{OC}}$. This trend was observed for the samples anodised at 20,60 and $120 \mathrm{~V}$, with their open-circuit potentials after $2 \mathrm{~h}$ equal to $180.4,279.0$ and $308.2 \mathrm{mV}$ vs. SCE, respectively. The surface of $\mathrm{Zr}$ anodised up to the voltage of $80 \mathrm{~V}$ attained the value of open-circuit potential which was substantially lower $(-26.0 \mathrm{mV}$ vs. SCE) than the remaining anodised surfaces (Table 1). The $E_{\mathrm{OC}}$ represents the so-called corrosion potential at which both anodic and cathodic corrosion reactions are occurring at the same rate. The value of $E_{\mathrm{OC}}$ is dictated both by the chemical composition and the thickness of the oxide layer. The decrease in the open-circuit potential vs. limiting anodisation voltage dependence observed at 80 and $100 \mathrm{~V}$ can be explained by the increase in sulphur content within those oxide layers.

Immediately after the $E_{\mathrm{OC}}$ measurements, potentiodynamic experiments were conducted (Fig. 5, c). The corrosion resistance parameters, such as corrosion potential, corrosion current density and polarisation resistance, are presented in Table 1. It should be noted that during anodic polarisation of the $\mathrm{Zr}$ samples significant passivation is usually encountered, which obscures the linear Tafel region. In order to obtain an estimate of corrosion current density for the investigated samples, the slopes were determined as lines that intercept the cathodic lines in the point of corrosion potential, which are tangent to the anodic part of the polarisation curve. Dashed lines were included in Fig. $5 \mathrm{c}$ to visualise how the cathodic and anodic slopes were determined. Results suggest that after anodising at $20 \mathrm{~V}$ corrosion resistance of zirconium in Ringer's solution was significantly improved. The corrosion current density for the $\mathrm{Zr} 20 \mathrm{~V}$ sample was estimated to be two orders of magnitude lower than that measured for the pretreated zirconium. A slight decrease in corrosion resistance compared to the sample anodised up to $20 \mathrm{~V}$ was noted for the $\mathrm{Zr} 60 \mathrm{~V}$ sample. Although the surface structure observed at SEM did not suggest any damage to the oxide layer, sulphur content in this sample was higher than that in the $\mathrm{Zr} 20 \mathrm{~V}$ sample. The similar trend was found for the sample anodised up to $80 \mathrm{~V}$, which was the least corrosion resistant among the other anodised $\mathrm{Zr}$ samples. This finding is in line with XPS results suggesting the maximum $\mathrm{S}$ content found in this sample. The corrosion current density decreased again for the $\mathrm{Zr}$ $100 \mathrm{~V}$ and $\mathrm{Zr} 120 \mathrm{~V}$ samples, with the decreasing sulphur content in their surfaces.

It was shown that the sulphate ion content in the oxide layers was increasing with the anodising voltage up to $80 \mathrm{~V}$, and at higher voltages, it was decreasing for the sample anodised at 100 and $120 \mathrm{~V}$. Therefore, it can be suggested that there is a link between these two observations. Authors will attempt to explain how could this came to be. It was demonstrated that sulphur present within the oxide layers on anodised zirconium was in the form of sulphates, implying that the layer was either composed of uniformly distributed sulphated zirconia or it contained sulphate rich regions. There

Table 1 Influence of anodic oxidation in sulphuric acid on corrosion resistance of zirconium

\begin{tabular}{lccccccc}
\hline Sample & $E_{\mathrm{OC}}, \mathrm{mV}$ vs. SCE & $E_{\text {corr }}, \mathrm{mV}$ vs. SCE & $\left|\beta_{\mathrm{c}}\right|, \mathrm{mV} \mathrm{dec}^{-1}$ & $\left|\beta_{\mathrm{a}}\right|, \mathrm{mV} \mathrm{dec}^{-1}$ & $R_{\mathrm{p}},{\mathrm{M} \Omega \mathrm{cm}^{2}}^{2}$ & $i_{\text {corr }}, \mathrm{nA} \mathrm{cm} \mathrm{c}^{-2}$ & $E_{\text {break }}, \mathrm{mV}_{\mathrm{vs} . \mathrm{SCE}}$ \\
\hline Zr 0 V & -474.5 & -468.0 & 219 & 325 & 1.53 & 37.2 & 575 \\
Zr 20 V & 180.4 & 172.9 & 63 & 120 & 175 & 0.10 & 1550 \\
Zr 60 V & 279.0 & 267.2 & 69 & 133 & 56.3 & 0.35 & 2595 \\
Zr 80 V & -26.0 & -34.7 & 90 & 305 & 17.1 & 1.76 & 3055 \\
Zr 100 V & 219.1 & 205.3 & 70 & 164 & 31.3 & 0.68 & 3685 \\
Zr 120 V & 308.2 & 300.1 & 86 & 169 & 43.1 & 0.57 & 3755 \\
\hline
\end{tabular}


are many reports on properties of sulphated zirconia synthesised by various methods [21-27]. Sulphated zirconia exhibits superacidity (highest among known solid acids, which is quantified by the Hammet acidity scale and is equal to -16.03 [23-25]) and can take part in hydrogen conduction due to the presence of protogenic sites [27]. These properties of sulphated zirconia led to the series of attempts to use it as a solid acidic catalyst for a large gamut of industrial processes, such as $n$-alkane isomerisation, esterification, etherification or condensation reactions [24]. It is also known that sulphated zirconia catalyses oxygen reduction reaction (ORR) which is beneficial in the design of direct methanol fuel cells [24, 25]. In light of the presented results, it can be theorised that some contributions to the corrosion current measured for S-rich anodised zirconium samples might originate from proton conduction within anodic oxide and/or ORR catalysed by the presence of sulphated zirconium oxide. Strong correlation between sulphur content in anodic films and corrosion current seems to satisfy such hypothesis. On the other hand, sulphur species incorporated in the oxide coating may have given rise to structural defects which would have a detrimental effect of the anticorrosion properties on the coating. In such a case, $\mathrm{O}_{2}{ }^{-}$ ions could be transported within the film in oxygen vacancies according to the point defect model [28]. Oxide coatings obtained at higher voltages where there were not much sulphate ions present in the oxide were no longer observed to accelerate corrosion of zirconium.

Finally, the resistance to pitting corrosion of zirconium specimens in Ringer's solution was assessed (Fig. 5d, Table 1). From the graph, it was clearly seen that the anodising had a positive effect on pitting corrosion resistance. Zirconium is susceptible to pitting in chloride solution [29] and it was determined that the protective passive layer on pretreated $\mathrm{Zr}$ sample ( $\mathrm{Zr} 0$ ) was broken down at approximately $575 \mathrm{mV}$ vs. SCE. Corrosion pits could be observed on the analysed surface afterwards (not shown). Anodising at $20 \mathrm{~V}$ shifted the value of breakdown voltage $\left(E_{\text {break }}\right)$ to $1550 \mathrm{mV}$ vs. SCE. Due to anodisation of zirconium specimens up to even higher voltages, the shift was more and more significant (Table 1). The presence of sulphate ions, if having effect at all, was not observed to have an impact on pitting corrosion resistance of anodised zirconium. The increase in the $E_{\text {break }}$ for the anodised zirconium samples can be attributed to the thickening of the oxide layers with the increasing voltage of anodisation. Thicker coatings were less prone to undergo the oxide breakdown at lower potentials and were protecting the underlying metal to a larger extent.

\section{Conclusions}

Present study on the effect of galvanostatic anodising of zirconium in sulphuric acid solution on chemical composition and corrosion resistance of zirconium in Ringer's solution surface showed that the voltage of anodisation had a large impact on surface properties of the obtained anodic oxide films. Relatively, large current density used throughout measurements led to the incorporation of sulphur species, which were identified as sulphates by XPS, at all applied limiting voltages. The maximum sulphur content was found after anodising at $80 \mathrm{~V}$. Anodic oxide layers formed at voltages greater than $80 \mathrm{~V}$ contained less sulphur than those obtained at lower voltages. The latter was explained by the hampering of the oxide layer growth rate beyond $80 \mathrm{~V}$ caused by the formation of gaseous oxygen on the surface of zirconium. It was found that high sulphur content in the oxide coating had a detrimental effect on the general corrosion resistance of zirconium, while its pitting corrosion resistance was found to be greater after treatment at higher voltages. The increase of corrosion current density determined for the anodised zirconium samples was explained by the presence of sulphated zirconia detected in the anodic films by XPS, which supports proton conduction and catalyses oxygen reduction reaction. Anodising at voltages above $80 \mathrm{~V}$ decreased sulphur content in the films and increased corrosion resistance of zirconium at the same time.

Acknowledgments This work was supported by the Polish Ministry of Science and Education under the "Diamond Grant" programme, research project no. DI 2012 024142. XPS measurements were supported by the Russian Foundation for Basic Research (Project 14-02-00006) and Government of Russian Federation (Act 211, agreement № 02.A03.21.0006).

Open Access This article is distributed under the terms of the Creative Commons Attribution 4.0 International License (http:// creativecommons.org/licenses/by/4.0/), which permits unrestricted use, distribution, and reproduction in any medium, provided you give appropriate credit to the original author(s) and the source, provide a link to the Creative Commons license, and indicate if changes were made.

\section{References}

1. Helsen JA, Missirlis Y (2010) Biomaterials: a Tantalus experience. Springer, Berlin

2. Sloppy JD, Lu Z, Dickey EC, Macdonald DD (2013) Growth mechanism of anodic tantalum pentoxide formed in phosphoric acid. Electrochim Acta 87:82-91

3. Macdonald DD (2011) The history of the point defect model for the passive state: a brief review of film growth aspects. Electrochim Acta 56:1761-1772

4. Tun Z, Noël JJ, Shoesmith DW (2008) Anodic oxide growth on Zr in neutral aqueous solution. Pramana-J Phys 71:769-776

5. McRae GA, Maguire MA, Jeffrey CA, Guzonas DA, Brown CA (2002) A comparison of fractal dimensions determined from atomic force microscopy and impedance spectroscopy of anodic oxides on Zr-25Nb. Appl Surf Sci 191:94-105

6. Van Overmeere Q, Proost J (2010) Stress-induced breakdown during galvanostatic anodising of zirconium. Electrochim Acta 55: $4653-4660$ 
7. Liu X, Huang A, Ding C, Chu PK (2006) Bioactivity and cytocompatibility of zirconia $\left(\mathrm{ZrO}_{2}\right)$ films fabricated by cathodic arc deposition. Biomaterials 27:3904-3911

8. Guo L, Zhao J, Wang X, Xu R, Lu Z, Li Y (2009) Bioactivity of zirconia nanotube arrays fabricated by electrochemical anodisation. Mater Sci Eng C 29:1174-1177

9. Shabalovskaya S, Anderegg J, Van Humbeeck J (2008) Critical overview of nitinol surfaces and their modifications for medical applications. Acta Biomater 4:447-467

10. Rokicki R, Hryniewicz T, Pulletikurthi C, Rokosz K, Munroe N (2015) Towards a better corrosion resistance and biocompatibility improvement of nitinol medical devices. J Mater Eng Perform 24: $1634-1640$

11. Zhu X, Kim K-H, Jeong Y (2001) Anodic oxide films containing $\mathrm{Ca}$ and $\mathrm{P}$ of titanium biomaterial. Biomaterials 22:2199-2206

12. Minagar S, Berndt CC, Wang J, Ivanova E, Wen C (2012) A review of the application of anodization for the fabrication of nanotubes on metal implant surfaces. Acta Biomater 8:2875-2888

13. Stern M, Geary AL (1957) Electrochemical polarization: I. A theoretical analysis of the shape of polarization curves. J Electrochem Soc 104:56-63

14. Biason Gomes MA, Onofre S, Juanto S, Bulhões LOS (1991) Anodization of niobium in sulphuric acid media. J Appl Electrochem 21:1023-1026

15. Vincent Crist B (2000) Handbook of monochromatic XPS spectra. Wiley, Berlin

16. Ardizzone S, Bianchi CL, Signoretto M (1998) Zr(IV) surface chemical state and acid features of sulphated-zirconia samples. Appl Surf Sci 136:213-220

17. Firsov MN, Nefedov VI, Langfelderova H, Serator M (1988) Electronic-structure of $\mathrm{M}_{2} \mathrm{Cu}\left(\mathrm{SO}_{4}\right)_{2}$ salts according to X-ray spectral and X-ray electronic data. Zh Neorg Khimii 33:2015-2018 in Russian

18. Wren AG, Philips RW, Tolentino CU (1979) Surface reactions of chlorine molecules and atoms with water and sulfuric acid at low temperatures. J Colloid Interf Sci 70:544-557

19. Audi AA, Sherwood PMA (2000) X-ray photoelectron spectroscopic studies of sulfates and bisulfates interpreted by $\mathrm{X} \alpha$ and band structure calculations. Surf Interface Anal 29:265-275
20. Zhuravlev YN, Zhuravleva LV, Poplavnoy AS (2003) Electronic structure of alkali metal sulfates. Russ Phys J 46:75-80

21. Zhai Y, Zhang H, Hua J, Yi B (2006) Preparation and characterization of sulfated zirconia $\left(\mathrm{SO}_{4}{ }^{2-} / \mathrm{ZrO}_{2}\right) / \mathrm{Nafion}$ composite membranes for PEMFC operation at high temperature/low humidity. J Membrane Sci 280:148-155

22. Younes MK, Ghorbel A, Rives A, Hubaut R (2004) Acidity of sulphated zirconia aerogels: correlation between XPS studies, surface potential measurements and catalytic activity in isopropanol dehydration reaction. J Sol-Gel Sci Techn 32: 349-352

23. Fărcasiu D, Li JQ, Cameron S (1997) Preparation of sulfated zirconia catalysts with improved control of sulfur content II effect of sulfur content on physical properties and catalytic activity. Appl Catal A-Gen 154:173-184

24. Yadav GD, Nair JJ (1999) Sulfated zirconia and its modified versions as promising catalysts for industrial processes. Micropor Mesopor Mater 33:1-48

25. Bi C, Zhang H, Zhang Y, Zhu X, Ma Y, Dai H, Xiao S (2008) Fabrication and investigation of $\mathrm{SiO}_{2}$ supported sulfated zirconia/ Nafion ${ }^{\circledR}$ self-humidifying membrane for proton exchange membrane fuel cell applications. J Power Sources 184:197-203

26. Yao Y, Guo B, Ji L, Jung K-H, Lin Z, Alcoutlabi M, Hamouda H, Zhang X (2011) Highly proton conductive electrolyte membranes: fiber-induced long-range ionic channels. Electrochem Commun 13: $1005-1008$

27. Liu Y, Ishihara A, Mitsushima S, Ota K-I (2010) Influence of sputtering power on oxygen reduction reaction activity of zirconium oxides prepared by radio frequency reactive sputtering. Electrochim Acta 55:1239-1244

28. Macdonald DD (1992) The point defect model for the passive state. J Electrochem Soc 139:3434-3449

29. Mamun A, Schennach R, Parga JR, Mollah MYA, Hossain MA, Cocke DL (2001) Passive film breakdown during anodic oxidation of zirconium in $\mathrm{pH} 8$ buffer containing chloride and sulfate. Electrochim Acta 6:3343-3350 